\title{
¿ES EL MODELO DEL TRIBUNAL TRIBUTARIO ESTADOUNIDENSE APLICABLE EN CHILE?
}

\author{
IS THE MODEL OF UNITED STATES' TAX COURT APPLICABLE IN CHILE?
}

\section{Hugo Hurtado Araneda*}

\section{INTRODUCCION}

La aplicación de las normas tributarias suscita una gran cantidad de controversias dado los diferentes criterios de interpretación que pueden sostener la entidad fiscalizadora por una parte y el contribuyente por la otra. En efecto, el primero busca aumentar la recaudación fiscal a través del cobro de impuestos mientras que el segundo trata de minimizar su carga tributaria pagando la menor cantidad de impuestos posible.

Resulta evidente entonces la necesidad de la existencia de un tercero imparcial que resuelva este conflicto utilizando criterios netamente técnicos que permitan dilucidar el sentido perseguido por la Ley en cada caso. Hasta la fecha, dicha función es ejercida en nuestro país por el Servicio de Impuestos Internos (SII), que es juez y parte en materias tributarias.

Para evitar esta injusticia, se encuentra en el Congreso un proyecto de ley (Boletín 3139-05) que busca corregir dicha distorsión jurídica creando tribunales tributarios independientes. Esta investigación busca determinar si el proyecto de ley podría basarse en el modelo de Tribunal Tributario existente en Estados Unidos para ser aplicado a Chile, toda vez que según se ha constatado la justicia tributaria en dicho país funciona de manera bastante eficiente.

Para determinar si el modelo estadounidense es aplicable en Chile estudiaremos

\footnotetext{
* Licenciado en Ciencias Jurídicas por la Pontificia Universidad de Católica de Chile, Master of Laws (LL.M.) in International Taxation, University of Florida, correo de contacto: hhurtadoa@hotmail.com
}

brevemente la controversia a nivel del Internal Revenue Service (IRS), el proceso ante el Tribunal Tributario estadonidense y por último se presentarán las conclusiones de esta investigación.

\section{LA CONTROVERSIA A NIVEL DEL IRS}

El Internal Revenue Service (IRS) es la institución encargada de fiscalizar el pago de los impuestos federales en Estados Unidos. La fiscalización inicial está a cargo de un auditor quien en caso de descubrir alguna disconformidad, notifica al contribuyente para que subsane la diferencia. Si este acata el reporte del funcionario, se resuelve el problema, pero si no lo hace, el auditor envía una carta para que dentro de 30 días pague o presente una apelación ante un Oficial de Apelaciones.

El Oficial de Apelaciones es por regla general un funcionario más calificado y con más experiencia que el auditor y su objetivo es llegar a un acuerdo con el contribuyente de forma tal de evitar un litigio innecesario. Para esto sostiene una serie de entrevistas y reuniones con el contribuyente y/o sus representantes. La información y declaraciones entregadas en estas reuniones no pueden por regla general ser utilizadas en juicio, ya que esto podría afectar la posibilidad de llegar a un acuerdo.

Durante toda la instancia administrativa ante el IRS, el contribuyente puede recurrir a la figura del Taxpayer Advocate, quien busca protegerlo, en caso que el IRS vulnere sus derechos denegando o dilatando devoluciones o exigiendo mayores requisitos que los determinados en la Ley para ciertos procedimientos.

$\mathrm{Si}$ las partes no llegan a una transacción, el contribuyente será notificado por el 
Oficial de Apelaciones para que pague dentro de 90 días o bien presente un reclamo en el Tribunal Tributario.

\section{PROCESO ANTE EL TRIBUNAL TRIBUTARIO}

Si el contribuyente no está de acuerdo con el IRS, tiene tres opciones para resolver el litigio: 1) Pagar el impuesto y recurrir a la Corte del Distrito (District Court); 2) Pagar el impuesto y recurrir a la Corte Federal de Reclamos (Court of Federal Claims) y 3) No pagar el impuesto y recurrir al Tribunal Tributario de Estados Unidos, el cual tiene jurisdicción nacional y su sede en Washington DC. El tribunal está constituido por 19 jueces regulares y por 5 jueces para casos abreviados. Además, existen algunos jueces regulares que se han retirado pero que aún revisan algunos casos. Cada juez tiene asistentes letrados y asistentes administrativos, contando con 238 personas que atienden todas las materias no jurídicas relacionadas a estos litigios.

Los jueces viajan por todo el país para conocer y fallar casos, visitando en total más de 75 ciudades de Estados Unidos por año. Sin embargo, toda la carga administrativa está centrada en la sede principal lo que permite aprovechar las economías de escalas.

Las estadísticas señalan que más de un 90\% de los casos son conocidos por el Tribunal Tributario de Estados Unidos. Lo anterior se debe a la existencia de procedimientos abreviados en los cuales el contribuyente puede comparecer personalmente, la posibilidad de reclamar del giro del impuesto sin haberlo pagado previamente, la especialización de los jueces y la oportunidad de tener un litigio en la ciudad donde reside el contribuyente.

El caso comienza con la remisión por carta certificada de un reclamo (Petition) al Tribunal Tributario, para que resuelva el asunto controvertido. El contribuyente puede pedir que el caso sea revisado en un procedimiento simplificado, llamado "S Case". Este último se caracteriza por ser un proceso para litigios cuya cuantía no excede US\$50.000 y ser un proceso abreviado cuyas normas procesales están diseñadas para permitir a personas no letradas comparecer en juicio. Una copia del reclamo es enviado al IRS para que la conteste debiendo hacerse cargo de todas las alegaciones del reclamante ya que de lo contrario podría concederse el hecho alegado. Normalmente no se confiere traslado al contribuyente.

Realizado lo anterior, el juez llama a las partes a realizar "estipulaciones", proceso en el cual deben consignar todo aquello en lo que están de acuerdo, dejando para resolución del juez solo los hechos controvertidos.

Terminado el proceso de "estipulaciones" se procede a la vista de la causa en una audiencia oral. Las partes deben presentar un Memorando previo al juicio en el cual resumen sus pretensiones y se acompañan las pruebas que se harán valer en juicio (testigos, peritos, documentos, etc.).

Concluida la vista de la causa, las partes pueden presentar escritos con observaciones dejando el caso en condiciones de ser fallado por el juez. El juez decidirá el caso utilizando el estándar de preponderancia de la prueba. Lo anterior significa que el juez no necesita una convicción absoluta del hecho, sino que otorgará la razón a aquel que tenga más probabilidades de estar en lo correcto.

El juez que conoció la causa redacta la sentencia y se la envía al Juez Jefe del Tribunal Tributario para su conocimiento. Si a este le parece bien el fallo, lo devuelve al juez redactor (lo cual constituye la regla general) pero si considera que debe ser revisada por otros jueces, como por ejemplo en caso que la sentencia contravenga una circular del IRS, se la envía al resto de los jueces regulares. Si ninguno de ellos manifiesta disconformidad, la sentencia es confirmada y si hay diferencia de opinión se cita al pleno el que resuelve el conflicto.

Las sentencias son susceptibles de recursos de reconsideración y de apelación ante el Circuito de la Corte de Apelaciones que corresponda a la residencia del contribuyente o al lugar donde la persona jurídica esté constituida.

Si el contribuyente pierde en la Corte de Apelaciones, puede recurrir a la Corte Suprema, pero en este caso, esta a su arbitrio puede decidir si acepta el caso. 


\section{CONCLUSIONES}

La pregunta inicial de esta investigación fue: ¿Es el modelo del Tribunal Tributario estadounidense aplicable en Chile? Nuestra respuesta es afirmativa, sin perjuicio de las adecuaciones necesarias para ajustarlo a nuestro derecho procesal y tributario.

A diferencia del modelo propuesto en el actual proyecto de Ley que propone un procedimiento escrito, el Tribunal Tributario estadounidense utiliza un procedimiento mixto en el cual las primeras y últimas presentaciones son escritas pero la parte medular es oral, y es precisamente en esta, en la cual el juez puede a través de una manera directa conocer las pretensiones y pruebas de las partes. Lo anterior permite que sea el juez y no un funcionario de menor rango quien decida la controversia y ayuda, además, a evitar corrupciones en el sistema. Pensamos que es muy importante que nuestro sistema procesal tributario adopte procedimientos modernos y eficientes siguiendo las tendencias de otras áreas del derecho como por ejemplo el procedimiento penal oral y laboral.

Para que el proceso tributario sea eficiente debe tener como base fundamental la economía procesal evitando litigios innecesarios que colapsen el sistema. En efecto, mu- chas veces puede ser más caro para el fisco tramitar un juicio que llegar a un acuerdo. En este sentido la economía procesal se alcanza permitiendo al SII y al contribuyente alcanzar acuerdos tanto en la instancia administrativa como en la instancia judicial. No obstante lo anterior, pienso que estas transacciones deben estar acompañadas de mecanismos de fiscalización que eviten la corrupción del sistema.

La existencia de un único tribunal que tenga jurisdicción nacional genera economías de escala que disminuyen los costos para el fisco de crear instalaciones y planta administrativa en todas las regiones como se propone en el proyecto de Ley. Los jueces confeccionarían una agenda de causas para impartir justicia en distintas ciudades del país donde podrían utilizar salas propias en las ciudades más importantes y de otros tribunales en ciudades más pequeñas.

La posibilidad de tener un procedimiento abreviado para casos de menor cuantía, la facultad del contribuyente de comparecer personalmente, la existencia de clínicas tributarias subsidiadas parcialmente por el Estado para gente de escasos recursos y la existencia de una oficina del contribuyente son herramientas de bajo costo que fácilmente pueden considerarse en nuestro sistema y que tienden a una justicia más equitativa y expedita. 